\title{
Sons do grande sertão
}

\author{
APRESENTAÇÃO DO CD
}

$\mathrm{P}$ RESUME-SE QUE LINHAS dedicadas à apresentação de um registro sonoro, fisicamente identificado como CD, devam trazer, em forma de amostragem, informações sobre sons captados - timbres, autores, conceitos, histórias grifadas, técnicas utilizadas, direção de arte envolvida, intencionalidade de forma, propósitos.

Sob a direção de Ivan Vilela, o CD recebeu sugestões de Wagner Dias, Marily Bezerra e Heinz Dieter Heidemann. Tornou-se uma realidade graças ao entendimento da Petrobras da relevância em patrocinar um inédito projeto sobre a repercussão no campo musical da obra do romancista de Cordisburgo.

Pode-se dizer que a compilação de Sons do grande sertão, áudio que acompanha esta edição da revista ESTUDOS AVANÇADOS, nasce da tentativa de concentrar, minimamente, inquietações sonoras provocadas, por um lado, pelo estudo da obra de João Guimarães Rosa, e, por outro, pelo transbordamento derivado desse lugar grandioso e transcendente, parte do que "restou do mundo original" ", o chamado grande sertão.

Na faixa 1 aparecem insinuados tessituras, histórias, formas e conceitos. A viola sertaneja, de arame, caipira, cabocla ou de feira, grudada nas mãos de Renato Andrade, anuncia, de certo modo, o gestual caudaloso do Velho Chico, o rosto do Andrequicé, os olhares da Taboca, o apreço de Manelim do Urucuia, as notas da Inhuma, o cheiro do Paredão, a cor do Mutum, o sabor e o significado do Morro da Garça.

Na faixa 2, no timbre do professor Antonio Candido, os versos da Canção de Siruiz, presentes no Grande sertão: veredas, "Urubu é vila alta, mais idosa do sertão: padroeira minha vida - vim de lá volto mais não ...”, recebem também altura melódica. Em nota enviada à editoria de ESTUDOS AVANÇADOS, Antonio Candido tece um pequeno fio de história:

A melodia divulgada neste número não é a Canção de Siruiz, que ninguém sabe de fato como possa ser. Quando estava sendo preparado um $\mathrm{CD}^{2} \mathrm{com}$ a leitura de trechos de Grande sertão: veredas por José Mindlin, Davi Arrigucci e eu, transpus para os versos de Guimarães Rosa a melodia de uma velha canção mineira que minha mãe ouvia em menina, entre 1900 e 1906, na cidade de Barbacena, onde morava então com a sua família. Era cantada por um lavador de assoalhos, Antonio Lino, entre outras que ficaram em nossa memória familiar. A letra original é a seguinte:

Gente vamo rezá - Por alma do Pai Carreiro, Que lá vai subindo o morro - Sem carro e sem candeeiro. 
Por isso mesmo - Eu não quero carreá,

O carreiro pega o boi - Mas não pega o marruá,

O carreiro pega o boi-Mas não pega o marruá.

Você pega o boi pintado - na porteira do currá.

O mais curioso é que a minha adaptação se espalhou, quem sabe por meio do

CD, de tal modo que, segundo me contaram, hoje a pseudo-Canção de Siruiz

foi adotada na própria região do autor...

Na faixa 3, Ivan Vilela em Paisagens transmite o ambiente do local, uma paisagem da alma, introspectiva, num ir e voltar a lugares distintos. Na faixa $\mathbf{6}$, em A força do boi, o compositor funde a força do animal à força do ritmo (boi) e às linguagens modal e tonal, num entrelaçar rítmico de textura densa. Um aboio precede a entrada dessa música trazendo mais nitidez à paisagem imaginada. Ele e sua viola são acompanhados por Ricardo Matsuda (violão), Roberto Peres (caxixi) e Dalga Larrondo (cerâmica). Na faixa 15, o mesmo violeiro traduz o universo de Rosa em Valsa para viver um grande amor, música que traz o sentimento e a dor de um amor vivido, sentido e não consumado entre Riobaldo e Diadorim.

O imaginário desperto em cada compositor pela obra roseana faz nascer frutos diversos. Na faixa 4, Rodrigo Delage, jovem compositor mineiro, prepara, a partir de coletas próprias, um Canto de vaqueiros, nas vozes de Pena Branca e Chico Lobo, cantadores-violeiros que trazem em seus cantos a beleza e a força das fontes onde beberam.

Na faixa 11 , ainda relatando um ofício sertanejo que caminha para a extinção, o próprio Rodrigo executa, com acompanhamento de Carlinhos Ferreira no tambor roncador, a composição Na ponta da zagaia. Esta é uma longa lança usada no enfrentamento com onças na região. Zagaieiro é o guerreiro que, em posse dessa arma, acua e encara a besta-fera comedora de gentes e criações. De criança ele aprende a mover um só olho e manter o outro fixo, olhando em frente. Quando acuada, a onça observa os olhos de seu oponente instante a instante. Descuido percebido, num átimo ela o ataca. Treinado, o zagaieiro desvia um de seus olhos enganando a onça, que salta sobre a ponta da zagaia. Esta, fixa ao chão, interpõe-se entre os combatentes e acolhe a onça que a abraça. Rodrigo, com a viola, desenha o embate acompanhado pelo roncador que nos remete ao esturro do bicho.

Na faixa 5, transcrevemos depoimento dado pelo contador de estórias José Maria Gonçalves, morador de Cordisburgo-MG:

É gostoso a gente ouvir nas nossas andanças, pelas paisagens sertanejas, o som do sertão. Os passarinhos cantando, como agora estamos ouvindo essa fogopagô fazendo esse fundo musical e vários passarinhos. Mesmo o vento passando entre as árvores. O vento levantando as filhas, assobiando nos paredões, entre as montanhas... 
Wagner Dias, compositor afeito ao mundo de Rosa, integrante do Estúrdio Quarteto, recria na faixa 7, com uma beleza roseana, instantes e sensações do primeiro encontro de Riobaldo e Diadorim em sua composição Rito.

Primeiro encontro, meu balanço

Medo e coragem na passagem

Peroba e rio, meu desafio

E as mãos atadas no ar...

Em Som de passarim, na faixa 12, Wagner traz numa ambientação sonora, natural e sertaneja, o tocante Miguilim, que é sonhado em seu cotidiano ao lado da mãe e brincando com seu irmão, Dito. Na voz de Élida Marques, acompanhada pelos músicos Fernando Machado (violão), Pedro Ribeiro e André Magalhães (percussão), saboreamos a beleza simples de:

Vai Miguilim e diz à sua mãe: "Mutum é tão bonito!", vai...

$\mathrm{E}$ adiante tem a música uma mudança súbita de andamento onde irrompe um galope. Galopando ao lado do irmão Dito vai Miguilim:

E no Papavento o Dito galopando, no Preto vai o Miguilim. Jé vaqueiro vai aos dois acompanhando para que não corram assim. Tantas cores no caminho, galopando, muito som de passarim, Jé vaqueiro vai aos dois acompanhando para que não corram assim.

Não foi por acaso que inúmeros violeiros desenharam nas cordas de seus instrumentos trechos e sensações da obra de Guimarães Rosa. Tavinho Moura, compositor de pérolas que perpassam os anos, descobre na viola uma nova maneira de nos contar acerca de suas belezas sonoras. Na composição Manuelzimda-crôa, na faixa 9, ele traz um momento do Grande sertão: veredas, quando Riobaldo e Diadorim, escondidos, esperam chegada de tropas e armamentos. No nada fazer, observam os passarinhos na beira do rio. Manuelzinho-da-crôa é o nome de um desses pequenos alados canoros. No fluir de sua viola e do violão de Beto Lopes, declama:

Que bonito é um barquinho saindo da barra, descendo pelo rio afora. Que bonito o Manuelzinho da Crôa cruzando a boca do Urucuia e querendo chegar lá na cachoeira do Poço Fundo, no riacho do Alegres, no córrego da Viúva, no ribeirão do Sumidouro, no riacho do Galho, lá, lá onde tem Caboclo D’água.

Para este CD foram escolhidos ponteados de viola, canções, narração de textos, fala de gente da região e sons da paisagem do cerrado. Foi selecionado um aboio, colocado na faixa 10 e interpretado pelo grupo paulistano Nhambuzim, com arranjo para vozes, violão, baixo, piano e percussão. No canto de Edson Penha, Joel Teixeira e Sarah Abreu se escuta:

Reberão das águas clara,

Bebedô das andorinha,

Pensamento dessa moça,

Meu coração adivinha... 
Nessa versão, a voz introdutória é do vaqueiro Manuelzão, extraída de gravação feita em vídeo, pelo jornalista e fotógrafo João Correia Filho, em trabalho de conclusão do curso de jornalismo, na Universidade Estadual Paulista (Unesp).

Noutro lugar, por outro caminho, dando andamento à sua dissertação de mestrado Paisagem sonora do espaço migrante, Rodrigo Passos Felicíssimo recolheu uma diversidade de sons, principalmente em Morro da Garça - MG, a partir de oficinas concebidas no Projeto Guimarães Rosa-Lugares, patrocinado pela Petrobras, no ano de 2005. Uma equipe formada por Julio de Paula, Regina Porto e pelo próprio Rodrigo Felicíssimo desenvolveu atividades com moradores da região em torno de temas como: a sensibilidade da escuta, o conhecimento de antigos e novos formatos sonoros, o treinamento em equipamentos de gravação, as técnicas de captação, o registro de depoimentos e a captação da própria paisagem sonora. Parte do áudio desse trabalho foi cedida ao IEA para ajudar a compor esse CD, que apresentamos nas faixas 8 e $\mathbf{1 4}$.

A viola, no passar dos anos e no fermentar das culturas, acabou se tornando porta-voz de grande parte da expressão cultural do povo do centro-leste do Brasil. Isolado muitas vezes de tudo e de todos, o sertanejo encontra na viola sua companheira no registro de histórias que as mãos não sabem escrever. Em versos rimados e metrificados, ele perpetua com fidelidade detalhes dos acontecidos fazendo com que sua história seja lembrada e seus atos repetidos pelos descendentes que vêm no curso dos tempos.

Na faixa 13, Paulo Freire aparece com a música Seca. Com as participações de Mário Manga (violoncelo) e Adriano Busko (percussão), esse tema pode sugerir o início da travessia do Liso do Suçuarão, a matança dos cavalos pelas mãos dos Hermógenes, o julgamento de Zé Bebelo ou mesmo o pacto de Riobaldo com o Tinhoso, cenas do Grande sertão: veredas.

O final de Grande sertão: veredas, na voz de José Mindlin, na faixa 16, encerra a proposta do CD. Desse modo, é indicado um fim em forma de travessia. Uma travessia para outras possibilidades sonoras - similares e diversas à apresentada. Segue o convite ao brinde. E daí, é ir ouvindo ...

Notas

1 Frase de José Mindlin, anotação de entrevista concedida à pesquisadora e atriz Mariana Huck.

2 Sete episódios do Grande sertão: veredas, CD dirigido por Marily Bezerra. 


\section{Estrutura do CD Sons do grande sertão}

I Inhuma do sertão (Renato Andrade)

Viola - Renato Andrade

Violão - João José da Silva

2 Canção de Siruiz (Versos do Grande sertão: veredas, de João Guimarães Rosa) Adaptação e interpretação de Antonio Candido

3 Paisagens (Ivan Vilela)

Viola - Ivan Vilela

Violão - Ricardo Matsuda

Percussão - Roberto Peres

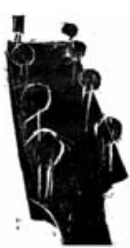

4 Canto de vaqueiros (Domínio público)

Voz e viola - Rodrigo Delage

Voz e viola - Chico Lobo

Voz - Pena Branca

Percussão - Carlinhos Ferreira

5 Narrativa sobre o sertão (José Maria Gonçalves) Voz - José Maria Gonçalves

6 A força do boi (Ivan Vilela) Viola e arranjo - Ivan Vilela Violão - Ricardo Matsuda Cerâmica - Dalga Larrondo Caxixi - Roberto Peres

7 Rito (Wagner Dias)

Esturdio Quarteto

Voz - Élida Marques

Violão - Fernando Machado e Wagner Dias Percussão - Pedro Ribeiro e Eduardo Contrera Baixo acústico - Pedro Macedo

8 Paisagem sonora I - Aves (Julio de Paula)

9 Manuelzim-da-crôa (Tavinho Moura)

Viola - Tavinho Moura

Violão - Beto Lopes
10 Aboio (Domínio público)

Grupo Nhambuzim

Voz e berrante - Edson Penha

Voz e violão - Joel Teixeira

Voz - Sarah Abreu

Percussão - André Oliveira e Rafael Mota

Baixo - Itamar Pereira

Piano e arranjos vocais - Xavier Bartaburu

11 Na ponta da zagaia (Rodrigo Delage)

Viola - Rodrigo Delage

Roncador (tambor de onça) - Carlinhos

Ferreira

12 Som de passarim (Wagner Dias)

Estúrdio Quarteto

Voz - Élida Marques

Violão - Fernando Machado

Violão e viola - Wagner Dias

Percussão - Pedro Ribeiro e André

Magalhães

13 Seca (Panlo Freire)

Viola - Paulo Freire

Violoncelo - Mario Manga

Percussão - Adriano Busko

14 Paisagem sonora II - Água (Julio de Paula)

15 Valsa para viver um grande amor (Ivan Vilela) Viola e arranjo - Ivan Vilela

Violão - Ricardo Matsuda

Rabeca - Luiz Henrique

16 Palavras finais de Grande sertão: veredas, de João Guimarães Rosa Voz - José Mindlim

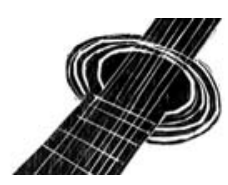




\section{Errata}

No texto de apresentação do CD "Sons do grande sertão", publicado na edição anterior de Estudos Avançados (número 58, p. 83-87), não foi informado ao leitor que a música Canção de Suruiz, reproduzida na faixa de número 2 , foi a composta pelo músico e compositor Luiz Henrique Xavier, a partir da melodia folclórica cantada e adaptada por Antonio Candido, para o CD distribuído em 1977, da coleção "Ler e Ouvir, l - Guimarães Rosa, 7 Episódios de Grande sertão: veredas", nas vozes de Antonio Candido, Davi Arrigucci Jr. e José Mindlin”, dirigido por Marly da Cunha Bezerra e Maria de Lourdes Nogueira Porto. 
O arquivo disponível sofreu correções conforme ERRATA publicada no Volume 21 Número 59 da revista. 